gehalten werben *. Unngeadjtet (ober wegen?) biejer (Enthaltung be=

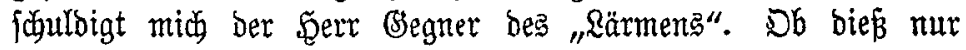
geichah, um bei ben Refern feir lautez $\mathfrak{x}$ ben gegen midj recht= fertigen zu fönnen, mag umunterjutht bleiben.

एs mag auch bafingeftellt bleiber, ob man bie Fertigftellung

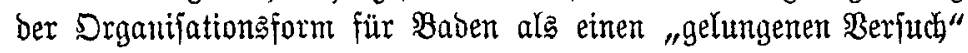
gelten lajien will. Unjere Statuter zetgen wenigitens, baß bie follegiale Berfafiung, über welhe hier alle Eines Sinneß

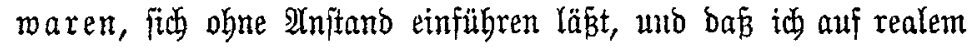
Boden itano, als id biefelbe gegenüber ber bureaufratififen Ein= zelleitung vertheibigte.

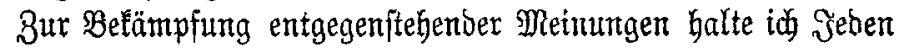
berechtigt, weldoger einiges Jnterefie an ber fünftigen Entwifflung

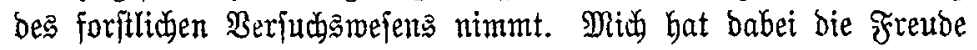

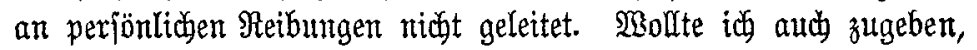
bás id mehr objeftiv bätte verfahren fömmen, fo erfparen mir die

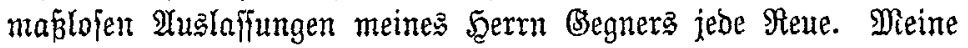

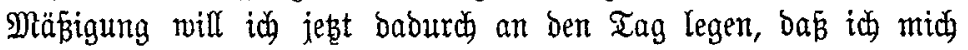

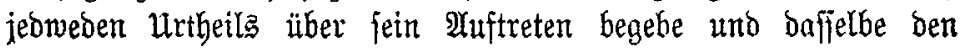
Eejern ber beiben Beitjowriften anbeimitefle.

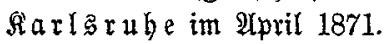

(C. St)uberg.

\title{
Jugduefen.
}

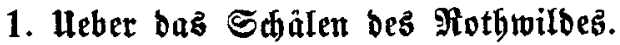

$\mathfrak{3}$ Monate $\mathfrak{M a ̈ r} z$ 1850 wurbe ein brei Morgen baltendes Felogrunbftüa auf mittelmäßigen fohlechtgedüngtem Boben als WSald=Enclave aufgeforjtet.

Der jährliche Bruttos\$achtertrag betrug pro Morgen 5 fl.,

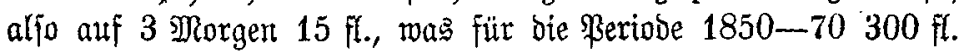

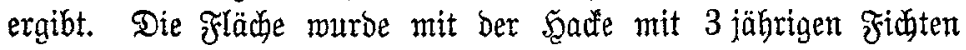
reihenweife bepflanzt. Befebt wurben

auf Rechnung 9000 Bflanzen, pro Mifle 2 fl. $=18$ fl., Taglöhne

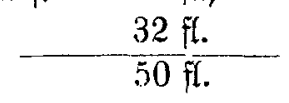

* शuङ ähnlicjen (Srünber wurbe aud jeither über ben Stand de马

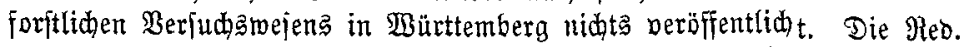
$18 \pi 1$. 
Die Rultur war volffänbig gelungen. Rleine F̧ehlftellen wurbent

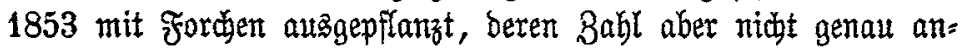
gegeben werben fann.

Im $\mathfrak{\text { ahre }} 1856$ murbe bie Rưltur mit anderen Beftänben

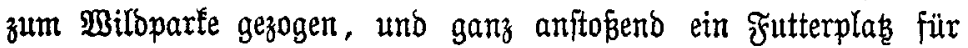

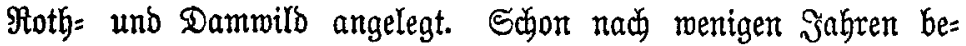

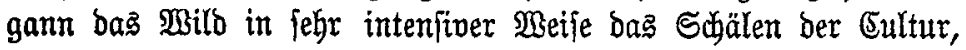
weldhes in ben Jahren 1864-66 immer größ̈ere Dimenfionen

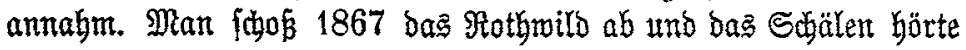
auf, obwobl ber Dammildftand blieb. Es ift eine Ihatfáde,

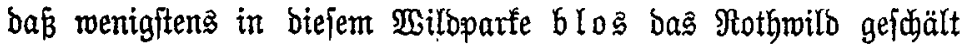
hat, bas Dammill aber $\mathfrak{n} i \mathrm{e}$, obwobl man in anberen Begenden gegentheilige SBeobachtungen gemadht baben will.

Die Siefern wurben in biefem Malbe nur einzeln ge=

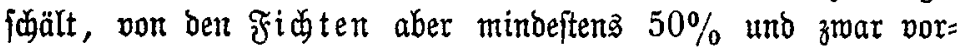
zugsmeife bie ftärf̌eren.

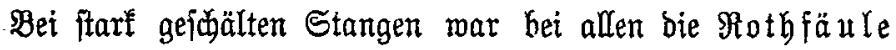
5-10' über bem Boben febr ftarf aufgetreter. Die gefwälten Stangen waren theilmeife halb, theils zal $1 / 5$ ber \$eripherie auf

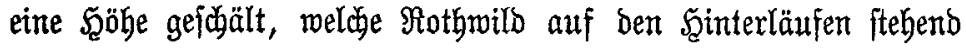
erreiden fonnte.

Borzugąweije haben ftarle Siride angefangen zu föllen, uno obgleid in biefiger Begend ein ftarfer Rothrillofiand im Freien rar, hat mant bamals feinen Sabaden hieburds auker an gejīälten 2rpfelbäumen erlebt.

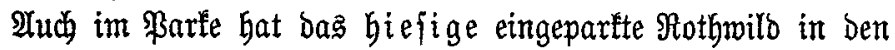
exften Jahhren nidht gefejält, fonbern es trat bieje Calantität erft

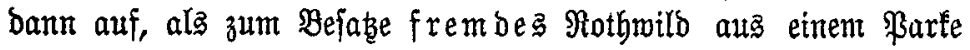
eingeję̧t woroen, wo bas Ecjälen zu Scauje war.

Der Fidtenbeftano hatte trob ber \$erlek̨ungen ftarfe \&ängen=

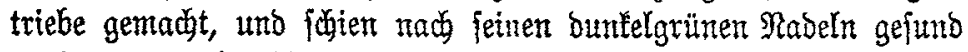
zu fein, und obwohl ein hoher $\mathfrak{U}$ mtrieb nidjt zu ermöglichen fahien, fo glaubte man boch bie Eultur erbalten zu fönnen. Der Seerbft: fturm am 26. Dftober 1870 bat aber ben Beftano volffommen rutnirt, indem horftreife die Fichten entwurzelt, bie ftarf gejchäl= 
ten an ben Shälplatten gebrodben uno bei ben Riefern bie Bipfel abgeiprengt wurben.

Die 20 fährige cultur mußte tabl abgetrieben merben, und

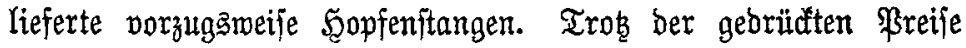
wurben zufammen 721 fl. $24 \mathfrak{f r}$. erzielt, was pro Morgen und Jăhr $36 \mathfrak{f l} .4 \mathfrak{f r}$. Bruttoeinnahme madyt.

Ridit obne Sntereffe find bie meiteren şeobachtungen über Das Schälent.

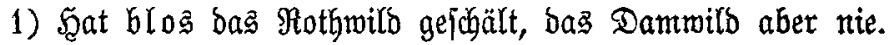

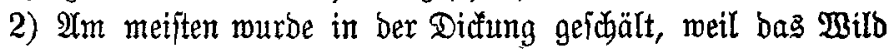
einmal am Ranbe fteyend, jofort an bie Futterraufen trat.

3) Borzuas̄weife murben die dominirenden Fiojten geidjält, eingepflanzte Riefent menig, einzelne noch ftehenbe \&ärchen faft gar nicht.

4) Die Sdyälplatten ber Fithten find nur theilmeife vernarbt, bie tiefergebenden nocy gar nicht, bagegen ooll sarz.

5. Bon ben Fichten find, uno zwar zumeift bie ftärferen Stangen auf 5 bis $10^{\prime}$ pom Boben rothfaul, und zmar min= beftem $50 \%$, bei fobmächer gefdülten Stangen ift bloz ber Rern bellroth gefärbt, bei ben ftarfaefduälten ijt ber ganze ßern fion weich und zamar jo, baf ben fanr.

(Es fcheinen aber auld hier zwei Gaftoren eingewirft zu haben, welche, wie bies auch fibon von anderer Seite vermuthet wurbe,

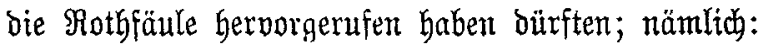

1. Das Hufforften alter Felogrünbe und

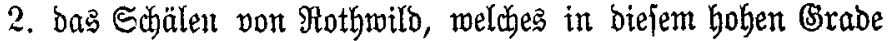
biejelben Folgen hat, wie ein ftarkes $\mathfrak{A}$ nharzen ber Fidite.

Die Rotbfäule ber Fiditen auf aufgeforfteten Felbern bat ber Unterzeidjnete ichon oft wahrgenommen, felbift auf trodienen Böbent, obgleidh es fatwer hält eine bejriesigetroe Erftärung für

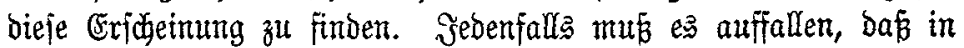

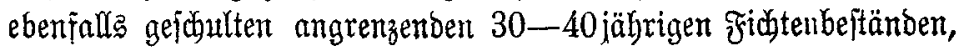
zwar auch rothfaule Stämme, aber in weit geringerer Menge vor= fommen, vielleidyt bebgalb, weil biefe Beftänto auf leinen Felb= gründen ftoffen. 
(Es werfen fich intereffante Fragen auf, warum in veridgics benen Diftriften verílebene Şolzarten vorzugąweife ober a uş

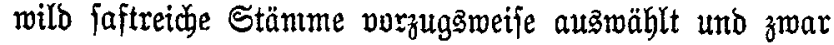

1. bie Fichte, wo fie müdujig und fräftig mar überall,

2. bie Riefer viel meniger,

3. bie Eidie, fo lange fie glatte Spiegelrinde hatte, überall unb fefr ftar:,

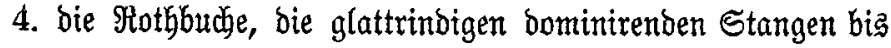
zur Raitelftärrée,

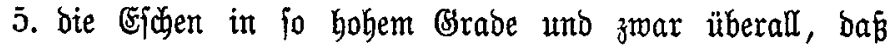
beren Erziehung ohne Schubgatter in einem Trilloparfe gerabezu unmöglid wäre.

(B) a $\mathfrak{r}$ ie geid̄ält murben bei mit Acer Pseudoplatanus, Pyrus torminalis, Populus canadensis, Aesculus hyppocastanum, Alnus glutinosa, Betula alba.

Oppentweiler im Jebruar 1871.

freiber von Sturmfeder.

\section{Ungarn's Filbreththum.}

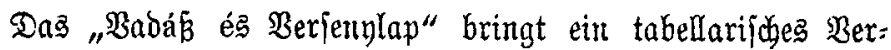
zeidnís über bie Menge des in vorigen Sagre erlegten $\mathfrak{B i l b e s .}$ Beidoffen murben Edelhiriche 381 (bie meiften, nämlidy 62 , in ber

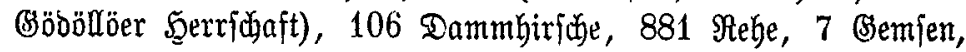
421 Milloldweine, 17,964 Şajen, (bie meiften, nämlid 3000, auf

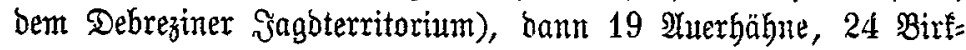
Gühner, 297 Şajelhühnter, 5065 Fajatte (oie meitten, nämlid) 1046, auf ber Fiftjaner Serrfojaft des (Frafen Franz (Eroöby), 11,000

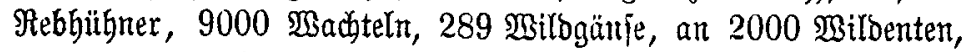

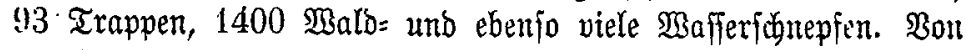
Raubwill wurben erlegt: 27 Bären (Gierwon 17 auf ber Mium=

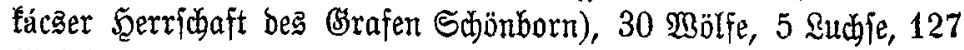

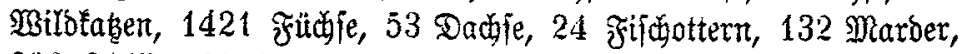
800 J̆ltiffe, 2053 Miejel, 138 Aroler u. f. w. Die Summe bes gefdofoffenen Milloes beträgt 103,746 ভtülf, bod fommt zu bemer= 